LBC 86.201

\title{
CONSOLATION BY JUSTICE: RELIGIOUS CONSCIOUSNESS OF PANDEMIC TRAUMATIC EVENTS
}

\author{
Andrey I. Makarov \\ Volgograd State University, Volgograd, Russian Federation \\ Tikhon V. Spirin \\ Volgograd State University, Volgograd, Russian Federation
}

\begin{abstract}
The article reviews secular and religious consciousness of the traumatic events of the coronavirus pandemic. Authors use the theory of cultural secularization for distinction of these two types of consciousness. In the modern age, the theory of "multiple worlds" developed, whose authors proved that people live in different worlds, realities and belong to different types of consciousness. The article analyzes two types of consciousness that create different life worlds of those who have these consciousnesses. The ethical component of understanding the universal traumatic event is analyzed in the aspect of the problem of connection between the concepts "consolation" and "justice". Consolation practices have been known since antiquity, and justice as an effect of establishing cosmic order is considered in many world cultures. In times of crisis, archaic layers of social consciousness become actualized, since it is required to use all resources of collective memory. The secular consciousness is characterized by the idea of man-made immanent justice: justice is established by the creators of human laws. Religious consciousness is based on the idea of a transcendental source of justice that is Creator of being who is a transcendental subject. Comprehension of a traumatic event for religious consciousness is a process of its normalization by giving it the quality of a just event that is necessary for ordering the world, restoring balance between the actions of people and the actions of nature. The psyche is calmed down by giving a just meaning by correlating it with the universal law of the Cosmos or the Creator's plan. Religious consciousness will always seek consolation in the aspect of the relationship between the immanent and transcendental levels of being, since its world is fundamentally dual, metaphysical.
\end{abstract}

Key words: pandemic, trauma, religious consciousness, consolation, justice, freedom.

Citation. Makarov A.I., Spirin T.V. Consolation by Justice: Religious Consciousness of Pandemic Traumatic Events. Logos et Praxis, 2021, vol. 20, no. 2, pp. 48-55. (in Russian). DOI: https://doi.org/10.15688/lp.jvolsu.2021.2.6

УДК 291.1

ББК 86.201

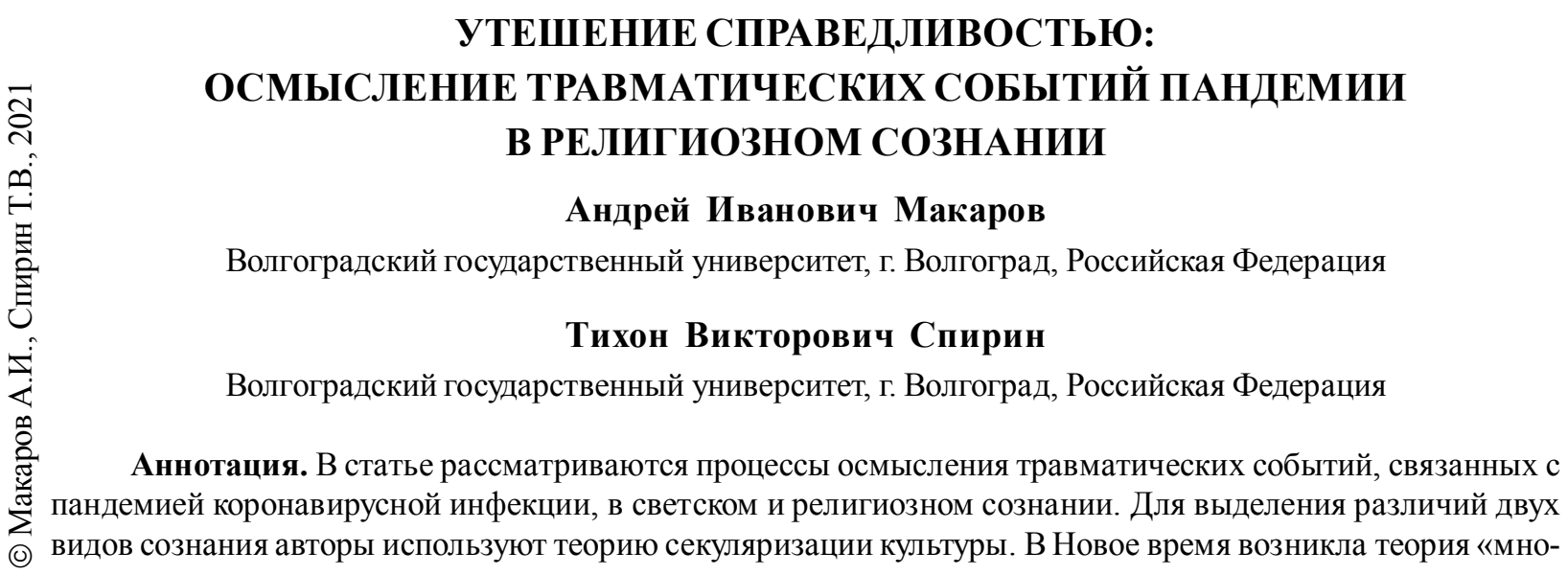


жественности миров», представители которой доказали, что люди живут в разных мирах, реальностях и являются носителями разных типов сознания. В статье анализируются два типа сознания, создающие для их носителей разные жизненные миры. Этическая составляющая осмысления всеобщего травматического события анализируется в аспекте проблемы связи понятий «утешение» и «справедливость». Практики утешения известны еще с античности, а справедливость как эффект установления космического порядка рассматривается во многих мировых культурах. В кризисное время архаические пласты общественного сознания актуализируются, так как требуется задействовать все ресурсы коллективной памяти. Для светского сознания характерно представление о рукотворной имманентной справедливости: она устанавливается творцами человеческих законов. Религиозное же сознание опирается на идею трансцендентного источника справедливости, то есть Создателя бытия, которым является трансцендентный субъект. Осмысление травмирующего события для носителей религиозного сознания - это процесс его нормализации через придание ему качества справедливого события, то есть необходимого для упорядочивания мира, восстановления равновесия между действиями людей и действиями природы. Через придание справедливого смысла посредством соотнесения с универсальным законом Космоса или замыслом Создателя успокаивается психика. Носитель религиозного сознания всегда будет искать утешения в аспекте отношений имманентного и трансцендентного уровней сущего, так как его мир принципиально двойственен, метафизичен.

Ключевые слова: пандемия, травма, религиозное сознание, утешение, справедливость, свобода.

Цитирование. Макаров А. И., Спирин Т. В. Утешение справедливостью: осмысление травматических событий пандемии в религиозном сознании // Logos et Praxis. - 2021. - T. 20, № 2. - C. 48-55. - DOI: https:// doi.org/10.15688/lp.jvolsu.2021.2.6

Не первый раз человечество сталкивается с масштабными травмирующими огромные массы людей событиями, разрушающими систему интерпретации смысла происходящего в истории. Сознание человека, по сути, хрупко, в особенности того, кто привык к рутине. Поэтому существует насущная необходимость в объяснительных моделях стремительно изменяющейся реальности под воздействием кризиса. Такие модели интерпретации реальности нормализуют травматические события, вносят порядок в хаос и тем самым терапируют индивидуальную психику и коллективное сознание. Например, мировые войны, разрушавшие привычное восприятие людьми реальности, приносили людям посттравматическое стрессовое расстройство, которое активно исследовали ученые. Историки анализировали причинно-следственные связи между травматическими событиями, чтобы упорядочить их; философы придавали таким событиям онтологический статус, устраивая бытие; терапевты и психиатры создавали методики психического исцеления. В этом смысле история и философия практические дисциплины - именно в этом их предназначение в кризисные эпохи. В спокойное время философы и историки могут «играть в бисер» в школьных аудиториях, просвещая и насыщая информацией обучающихся, но в кризисные времена эта функция уходит на периферию.
Например, во время пандемии с изоляцией людей и спешного перевода преподавания гуманитарных дисциплин на дистантные формы коммуникации массы людей оказались перед лицом усиливающейся имитации образования и замены общения его эрзац-формами. Это может стать причиной глобального посттравматического синдрома всего общества. Поэтому актуальной становится именно практическая философия.

Введение режима социального разобщения и карантина в большинстве стран мира вновь поставили перед философией задачу устроения бытия современного человека, который о-бес-покоен, то есть критически лишен покоя, порядка и ритма, способного обеспечить относительную стабильность психики. В 2020 г. резко увеличилось количество депрессий. Человек, столкнувшийся на карантине со своим Я, пережил особый экзистенциальный опыт, подобный опыту анахоретов различных религиозных традиций. М.К. Мамардашвили писал: «...человеческое существо есть существо трансцензуса (от слова “трансцендирование”), что означает существо, способное выходить за свои собственные пределы» [Мамардашвили 2019, 76]. Мы предполагаем, что именно осознание себя в качестве трансцендирующего субъекта породило такую неблагоприятную картину реальности. 
В изоляции люди, оставшись наедине с собой, получили ужасную возможность встать перед зеркалом и увидеть себя, свою экзистенцию. Некоторые обнаружили там пустоту или смутный образ существа без будущего. До этих событий индивиды отвлекались от осмысления своего Я участием в интенсивных социальных практиках, а в самоизоляции человеку пришлось долгое время находиться одному, что влекло его к размышлениям о собственном существовании. Однако рефлексия без метода или опыта приобщения к традиции, которая само по себе уже есть способ определенного отношения к миру и истории, будут плоскими, скользящими по поверхности событий, что не может принести утешения.

Утешение - это важная тема, присутствующая как в психологии, так и в философии. Для психологии есть практически только один повод для утешения - это смерть или болезнь. В других случаях депрессивных состояний прибегают не к утешению, а к излечению. Обширная религиозная утешительная литература содержит много других поводов для утешения: изгнание, бедность, политический провал, болезнь, кораблекрушение и старость [Gagarin 2010]. Что общего у всех этих причин, что является глубинной причиной страдания, которое требует утешения? Нарушение равновесия в мире. Нарушение равновесия традиционно, начиная с античной философии, связывается с понятием несправедливости (adikia), так как со времен Солона «естественным регулятором порядка становится справедливость» [Вернан 1988, 108]. Таким образом, пересекаются утешение и справедливость. Это делает актуальной разработку наряду с медицинскими терапевтическими практиками философских практик, терапирующих сознание людей. Большинство людей не обладает «инструментами» психотерапии и практической философии, которые помогают человеку разобраться в логике собственной жизни. Поэтому как когда-то книга Боэция «Утешение философией» была основой средневековых методов установления экзистенциального порядка индивидуальной и коллективной психики, так и теперь нужны соответствующие тексты. Мы не претендуем на создание такого текста в этой статье; цель ее - поставить проблему.
Глобальное и для многих травматическое событие пандемии побуждает людей искать причины произошедшего. Знание последних способно упорядочить историю, и значит, снять ужас, подпитываемый ее хаотизацией. В этих условиях даже важнее поиска исторических фактических причин пандемии найти правильные вопросы, проблематизировать ситуацию так, чтобы стали видны отдельные реальные проблемы, чтобы запутанная внешняя ситуация не внушала страх через запутывание сознания индивида, - это является задачей именно гуманитарных наук, призванных нормализовать реальность через ее категоризацию и логизацию. Одним из таких, на наш взгляд, является вопрос о смысле событий, ввергнувших людей в травматический процесс глобального социального эксперимента, поставленного историей глобализации экономических, политических и социальных контактов. В Новое время философия (в частности, представители теории «множественности миров») доказала, что люди живут в разных мирах, реальностях, потому что являются носителями разных типов сознания.

В этой статье нас будет интересовать вопрос о способе утешения, приведения сознания к гармонии в ситуации кризиса интеллектуальными ресурсами религиозного сознания. Понятно, что этот тип сознания сегодня можно рассматривать лишь на фоне доминирующего разрелигиозненного (светского) типа сознания. У носителей этих двух типов сознания различаются категории мышления и психологические реакции на происходящее. Нужно специально отметить, что религиозное сознание не отторгает рациональное мышление, но включает в него категории, присущие религиозным представлениям о реальности, как об этом писал Генри Драммонд.

Для носителей религиозного сознания, помимо антропных субъектов, есть еще неантропные субъекты, которые являются полноправными участниками трансформирующих бытие событий. На какую бы систему идей не опиралось религиозное сознание: будь то монотеистическая идеология авраамических религий или представления об истинно сущем бушменов, - количество субъектов всегда будет на порядок выше, чем у носителя светского сознания; это пре- 
красно продемонстрировано в классических трудах Мирчи Элиаде.

В сложившейся ситуации ковидного социального эксперимента носители и религиозного, и светского сознания по необходимости обращались к этическому аспекту в интерпретации травматического события, ведь произошедшие глобальные события трагичны, связаны со смертью людей. Смерть требует размышлений о ней в этической плоскости, если она насильственная. И как ни странно может показаться на первый взгляд, но в части общественного сознания возник вопрос о субъекте смертоносного деяния: кто и зачем убил? Но ведь вирус - это неантропная сила, не обладающая субъектностью. Однако - как было отмечено Е.Л. Березович и О.Д. Суриковой - вирус подвержен антропоморфизации в сознании человека. «Причины, почему образ болезней активно используется в проклятиях, - это страшные симптомы и последствия болезни, иррациональность ее природы для наивного сознания, а также тот факт, что болезни нередко подвергаются антропоморфизации, наделяются свойствами деятельного субъекта» [Березович, Сурикова 2019, 37 ].

Если вирус представляется субъектом и осмысляется в этическом ключе - значит есть основание рассмотреть подобную интерпретацию как религиозную или квазирелигиозную. Квазирелигиозность характерна для так называемого «светского сознания», лишенного критического модуса мышления. Нужно ли говорить, что критическое мышление - это редкость для современного человека, погруженного в атмосферу пропагандистской речи, которой были переполнены СМИ, пишущие о пандемии. Пропагандистским типом речи в теории риторики называется неаргументированная речь, ориентированная на внушение, а не на убеждение. Например, совершенно очевидно, что в пропаганде антиковидных мер СМИ сделали упор на формирование страха и чувства вины. Это типичные признаки пропагандистской внушающей речи. Это уже было проанализировано учеными, в том числе медиками. Дискуссии о мерах, предпринимаемых администрациями регионов и федеральными органами, - неотьемлемая часть критического мышления - были прямо запрещены медикам приказом Минздрава от
27.10.2020, из которого следовало, что сотрудникам учреждений, подведомственных Министерству здравоохранения РФ, необходимо согласовывать в устной или письменной форме с пресс-службой министерства свои комментарии на тему COVID-19 [Минздрав web] ${ }^{1}$. И хотя запрет касался руководителей учреждений и главных внештатных специалистов, понятно, что это ограничивало если не право, то возможность дискуссий в среде специалистов.

Введенный режим самоизоляции, в отличие от режима насильственного карантина, предполагает самодисциплину и внутреннюю цензуру мысли и действия, которую СМИ единолично, конечно, сформировать не могут, так как это коллективная задача семьи, образовательных учреждений и общественных институций. СМИ стали спешно пытаться сформировать страх смерти и чувство вины за нарушение антиковидных мер, - все это активизировало в светском сознании квазирелигиозные когнитивные схематизмы мышления. Поэтому в части общественного сознания произошла антропоморфизация вируса, наделение его субъектностью; и возник вопрос: справедлива ли судьба, принесшая пандемию? Фатализм также подпитывается политикой СМИ, которые не пишут о расследовании причин возникновения вируса и логике мер, предложенных ВОЗ. Вернее, наспех были вброшены версии такой логики, но дискуссии все были свернуты, а это означает, что верификацию предлагаемый СМИ дискурс не прошел. Но там, где нет системных разумных объяснений, начинают активизироваться архаические программы сознания.

Таким образом, в части общественного сознания закономерно возник вопрос о судьбе и справедливости происходящего. Закономерность этого вопроса состоит в том, что этические структуры сознания отвечают за утешение во время горя и кризисов издревле это хорошо исследовано на примере Древней Греции Ж.П. Вернаном [Вернан 1988]. Также и Боэций считал, что образ и понятие справедливости не только указывают на травматическую ситуацию, но и дают основания для утешения в случае установления справедливости происходящих событий. Как мы уже отметили, таким установлением традиционно занимаются историки и философы. 
Два разбираемых типа сознания так интерпретируют справедливость. Для светского сознания характерно представление о рукотворной, или имманентной, справедливости, когда справедливость устанавливается законодательством. В теории Джона Ролза справедливость анализируется через экономические и социальные процессы, то есть идея справедливости развивается только в нашем мире и не выходит за его пределы. «Справедливость как нравственное явление - это общественное требование к такому поведению людей, которое соответствует как личным, так и общественным интересам и отвечает интересам развития общества по пути прогресса», - пишет В.Д. Филимонов [Филимонов 2013, 102-103].

Религиозное сознание опирается на идею трансцендентного источника справедливости. Общественные институты не способны дать обоснование справедливости, так как каждый человек либо равен в своей группе другим (например, брахманы в индуизме), либо отдельно взятый индивид равен каждому человеку на земле (идея всеобщего равенства). Для языческого религиозного сознания справедливость - это соответствие деяний или событий космическому Закону (nomos); в теизме только тот, кто создал мир, может осуществлять смысловое наполнение понятия справедливости.

Осмысление всеобщих травматических событий через идею справедливости - это устоявшаяся практика утешения страстей горя, злости, досады и т. п. Например, в иудаизме осмысление библейскими пророками первого разрушения Храма. Более близкое нам осмысление Николаем Касаткиным (в русской православной традиции - Николай Японский) поражений русской армии в русско-японской войне 1904-1905 гг.: «Бьют нас японцы, ненавидят нас все народы, Господь Бог, по-видимому, гнев Свой изливает на нас. Да и как иначе? За что бы нас любить и жаловать? Дворянство наше веками развращалось крепостным правом и сделалось развратным до мозга костей. Простой народ веками угнетался тем же крепостным состоянием и сделался невежествен и груб до последней степени; служилый класс и чиновничество жили взяточничеством и казнокрадством, и ныне на всех степенях служения - поголовное самое бессовестное казнокрадство везде, где только можно украсть. Верхний класс - коллекция обезьян - подражателей и обожателей то Франции, то Англии, то Германии и всего прочего заграничного; духовенство, гнетомое бедностью, еле содержит катехизис - до развития ли ему христианских идеалов и освещения ими себя и других?.. И при всем том мы - самого высокого мнения о себе: мы только истинные христиане, у нас только настоящее просвещение, а там - мрак и гнилость; а сильны мы так, что шапками всех забросаем... Нет, недаром нынешние бедствия обрушиваются на Россию - сама она привлекла их на себя. Только сотвори, Господи Боже, чтобы это было наказующим жезлом Любви Твоей! Не дай, Господи, в конец расстроиться моему бедному Отечеству! Пощади и сохрани его!» [Японский 2004, 119]. Из этого текста видно, что народ совершил огромное количество грехов, поэтому претерпевает наказание. Также ярким примером может служить идея Кали-юги в индуизме, особая эпоха, которая является последствием поступков династии Яду.

Осмысление травмирующего события как справедливого для религиозного сознания необходимо для упорядочивания мира и психики посредством соотнесения с универсальным законом Космоса или замыслом Создателя. Свобода Создателя осмысляется как условие справедливости, а реализация свободы человеком порождает в мире обстоятельства, требующие акта трансцендентной справедливости.

Представители христианства наиболее глубоко проанализировали идею свободы, которую можно продемонстрировать на евангельских словах Иисуса Христа. Христос говорит представителям партии фарисеев об их посмертном существовании: что их ждет, если они продолжат вести настоящий образ жизни и не изменятся, а также Иисус Христос предоставляет им альтернативу, именно выбор пути и есть акт реализации свободы.

Логика отношений идеи справедливости и идеи свободы в религиозном сознании проясняется, если оттолкнуться в рассуждениях о свободе от идей Бенедикта Спинозы, которые обобщил В.П. Лега: «Спиноза дает опре- 
деление того, что такое свобода: свобода есть то, что само определяет себя к действию или действует в соответствии с необходимостью только своей собственной природы. То есть свобода противопоставляется не необходимости, а принуждению. Свободным является тот, кто сам определяет себя в своем собственном действии. Поэтому понятно, что свободным в собственном смысле является только Бог. Только Бог, или субстанция, является причиной самой себя; только Бог Сам определяет Себя к действию и действует в соответствии с необходимостью только Своей собственной природы... Человек может действовать свободно, то есть непринужденно (ведь свобода противопоставляется не необходимости, а принуждению). Человек может свободно выбирать, свободно действовать в рамках познанной необходимой цепи явлений. И как только человек начинает действовать свободно, понимая, что он часть природы, и включен в необходимую связь явлений, тогда он и становится действительно свободным. А свободным он становится тогда, когда он не просто понимает, но и познает необходимую связь явлений» [Лега web]. Человек не закрепощен обстоятельствами, а находится в некоторых условиях, где он может реализовывать свою свободу; одним из условий является определенный образ блага, который принимает религиозное сознание, тем самым религиозный человек выбирает между двумя вариантами, которые можно сформулировать следующим образом: путь блага или путь зла. В условия реализации свободы также включены определенные постулаты, которые описывают образ блага и образ зла; выбрав путь, человек должен понимать, что ждет его в будущем, например, каково будет его посмертное существование.

Появление пандемии может принять различные объяснения в контексте религиозного сознания, но вопрос о справедливости будет так или иначе задан и ответ будет искаться в аспекте отношений имманентного и трансцендентного уровней сущего. Вопрос о справедливости произошедшего в данном случае тоже возникнет, так как есть традиция искать сомасштабные Космосу или Провидению ответы. Идея трансцендентного вмешательства для установления справедливости способна объяснить носителю религиозного сознания логику травматических событий во время пандемии коронавирусной инфекции. Утешением может быть следующая интерпретация: травматическое событие обусловлено негативной динамикой мира и человечества, которое отошло от закона бытия, состоящего для христиан в спасении души, для буддистов - в идее освобождения, для спиритуалистов - в перемещении после смерти на более высокий (или качественный) уровень бытия и пр. В случае, когда человечество отошло от правил спасения / освобождения / трансгрессивности души, возникает условие для восстановления справедливости как равновесия между нормой и преступлением, предполагающим воздаяние.

С точки зрения светского сознания «съеденная летучая мышь» и миллионы смертей несоизмеримы, но с точки зрения религиозного сознания «съеденная летучая мышь» и миллионы смертей соизмеримы, потому что коронавирусная инфекция, появившаяся из-за такого случая - это лишь инструмент, который используется для восстановления справедливости после долгой негативной динамики пути человечества, отклонения от дао.

Таким образом, можно видеть, что религиозное сознание базируется на этических идеях, этические идеи имеют отношение в данном виде сознания к трансцендентному. Человек, носитель религиозного сознания, начинает процесс анализа: сопоставление образа человека, полученного когда-то из нематериального мира с тем образом человека, который есть сейчас, а всемирное травматическое событие становится реакцией трансцендентного на длительные деструктивные практики человека, отдаляющегося от того образа, который получен из нематериального мира. И как бы странно ни выглядело данное суждение для носителей светского сознания, нельзя игнорировать смыслы, и значит, - экзистенциальные интересы религиозной части общества.

\section{ПРИМЕЧАНИЕ}

${ }^{1}$ Данное сообщение (материал) создано и (или) распространено иностранным средством массовой информации, выполняющим функции иностранного агента, и (или) российским юриди- 
ческим лицом, выполняющим функции иностранного агента.

\section{СПИСОК ЛИТЕРАТУРЫ}

Березович, Сурикова 2019 - Березович Е.Л., Сурикова О.Д. Названия болезней в русских проклятиях // Этнолингвистика. Ономастика. Этимология: материалы Междунар. науч. конф. (г. Екатеринбург, 9-13 сент. 2019 г.). Екатеринбург: Изд-во Урал. ун-та, 2019. С. 37-40.

Бурханов 2016 - Бурханов Р.А. Трансцендентальное, имманентное и трансцендентное в философии Иммануила Канта // Исторические, философские, политические и юридические науки, культурология и искусствоведение. Вопросы теории и практики. Тамбов: Грамота, 2016. № 3, ч. 2. С. 34-36.

Вернан 1988 - Вернан Ж.-П. Происхождение древнегреческой мысли. М.: Прогресс, 1988. 224 с.

Лега web - Лега В.П. Философия нового времени. Бенедикт Спиноза [Седмица.RU] // https:// www.sedmitza.ru/lib/text/431778.

Мамардашвили 2019 - Мамардашвили М. Беседы о мышлении. СПб.: Азбука, 2019.

Минздрав запретил... web - Минздрав запретил врачам публично высказываться о коронавируce. 28 октября 2020 [Meduza] // https://meduza. io/news/2020/10/28/minzdrav-zapretil-vrachampublichno-vyskazyvatsya-o-koronaviruse? utm_source $=$ website\&utm_medium $=$ push $\&$ utm_campaign=browser_news.

Родзинский 2003 - Родзинский Д. Л. Сознание античного мудреца. М.: Аграф, 2003.

Узланер 2008 - Узланер Д. Расколдовывание дискурса: «Религиозное» и «светское» в языке нового времени // Логос. 2008. № 4 (67). С. 140-159.

Филимонов 2013 - Филимонов В.Д. Гуманизм как принцип права // Государство и право. 2013. № 1. С. 102-108.

Элиаде 1999 - Элиаде М. Очерки сравнительного религиоведения: пер. с англ. М.: Ладомир, 1999.

Элиаде 1994 - Элиаде М. Священное и мирское / пер. с фр., предисл. и коммент. Н.К. Гарбовского. М. : Изд-во МГУ, 1994.

Японский 2004 - Японский Н. Дневники святого Николая Японского. В 5 т. Т. 5 / сост. К. Накамура. СПб.: Гиперион, 2004.

Bonhoeffer Dietrich 1970 - Bonhoeffer Dietrich. Letter to Eberhard Bethge, 29 May 1944 // Letters and Papers from Prison / ed. by Eberhard Bethge, transl. by Reginald H. Fuller. Munich: Christian Kaiser Verlag, 1970. P. 310-312.
Gagarin 2010 - Gagarin M. The Oxford Encyclopedia of Ancient Greece and Rome. In 7 vols. Vol. 1. Oxford: Oxford University Press, 2010.

\section{REFERENCES}

Berezovich E.L., Surikova O.D., 2019. Names of Diseases in Russian Curses. Ethnolinguistics. Onomastics. Etymology: Materials of an International Scientific Conference (Yekaterinburg, September 9-13, 2019). Yekaterinburg, Izdatelstvo Uralskogo universiteta, pp. 37-40.

Burkhanov R.A., 2016. Transcendental, Immanent and Transcendental in the Philosophy of Immanuel Kant. Historical, Philosophical, Political and Legal Sciences, Cultural Studies and Art History. Questions of Theory and Practice. Tambov, Gramota Publ., no. 3, pt. 2, pp. 34-36.

Vernant J.-P., 1988. The Origin of Ancient Greek Thought. Moscow, Progress Publ., 1988.

Lega V.P. Philosophy of Modern Times. Benedict Spinoza. Sedmitsa.RU. URL: https://www. sedmitza.ru/lib/text/431778.

Mamardashvili M., 2019. Conversations About Thinking. Saint Petersburg, Azbuka Publ.

The Ministry of Health Has Banned Doctors from Speaking Publicly About the Coronavirus. October 28, 2020. Meduza. URL: https://meduza. io/news/2020/10/28/minzdrav-zapretil-vrachampublichno-vyskazyvatsya-o-koronaviruse? utm_source=website\&utm_medium $=$ push \& utm_campaign $=$ browser_news.

Rodzinsky D.L., 2003. Consciousness of the Ancient Sage. Moscow, Agraf Publ., 2003.

Uzlaner D., 2008. Disenchantment of Discourse: "Religious" and "Secular" in the Language of Modern Times. Logos, no. 4 (67), pp. 140-159.

Filimonov V.D., 2013. Humanism As a Principle of Law. State and Law, no. 1, pp. 102-108.

Eliade M., 1999. Essays on Comparative Religious Studies: Translated from English. Moscow, Ladomir Publ.

Eliade M. Sacred and Secular. Moscow, Izdatelstvo MGU, 1994.

Yaponsky N., 2004. Diaries of St. Nicholas of Japan. In 5 vols. Vol. 5. Saint Petersburg, Hyperion.

Bonhoeffer Dietrich, 1970. Letter to Eberhard Bethge, 29 May 1944. Letters and Papers from Prison. Munich, Christian Kaiser Verlag, pp. 310-312.

Gagarin M., 2010. The Oxford Encyclopedia of Ancient Greece and Rome. In 7 vols. Vol. 1. Oxford, Oxford University Press. 
А.И. Макаров, Т.В. Спирин. Утешение справедливостью: осмысление травматических событий пандемии

\section{Information About the Authors}

Andrey I. Makarov, Doctor of Sciences (Philosophy), Professor, Associate Professor, Department of Philosophy, Volgograd State University, Prosp. Universitetsky, 100, 400062 Volgograd, Russian Federation, socphil@volsu.ru, https://orcid.org/0000-0002-9056-3741

Tikhon V. Spirin, Postgraduate Student, Department of Philosophy, Volgograd State University, Prosp. Universitetsky, 100, 400062 Volgograd, Russian Federation, spirin.tikhon@gmail.com, https://orcid.org/0000-0003-1244-957X

\section{Информация об авторах}

Андрей Иванович Макаров, доктор философских наук, профессор, доцент кафедры философии, Волгоградский государственный университет, просп. Университетский, 100, 400062 г. Волгоград, Российская Федерация, socphil@volsu.ru, https://orcid.org/0000-0002-9056-3741

Тихон Викторович Спирин, аспирант кафедры философии, Волгоградский государственный университет, просп. Университетский, 100, 400062 г. Волгоград, Российская Федерация, spirin.tikhon@gmail.com, https://orcid.org/0000-0003-1244-957X 